\title{
A large pterosaur limb bone from the Kaiparowits Formation (late Campanian) of Grand Staircase-Escalante National Monument, Utah, USA
}

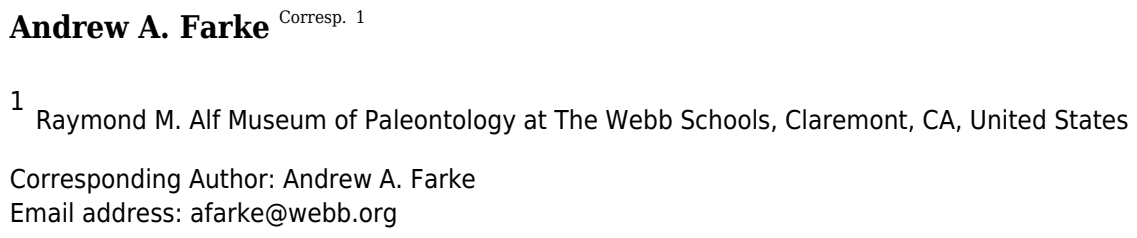

Pterosaurs were widespread during the Late Cretaceous, but their fossils are comparatively rare in terrestrial depositional environments. A large pterosaur bone from the Kaiparowits Formation (late Campanian, 76-74 Ma) of southern Utah, USA, is tentatively identified as an ulna, although its phylogenetic placement cannot be precisely constrained beyond Pterosauria. The element measures over $36 \mathrm{~cm}$ in preserved maximum length, indicating a comparatively large individual with an estimated wingspan between 4.3-5.9 m, the largest pterosaur yet reported from the Kaiparowits Formation. This size estimate places the individual at approximately the same wingspan as the holotype for Cryodrakon boreas from the penecontemporaneous Dinosaur Park Formation of Alberta. Thus, relatively large pterosaurs occurred in terrestrial ecosystems in both the northern and southern parts of Laramidia (western North America) during the late Campanian. 


\section{A large pterosaur limb bone from the Kaiparowits}

2 Formation (late Campanian) of Grand Staircase-

\section{Escalante National Monument, Utah, USA}

5 Andrew A. Farke ${ }^{1}$

6 Raymond M. Alf Museum of Paleontology at The Webb Schools, Claremont, California, USA

8 Corresponding Author:

9 Andrew A. Farke

10 Raymond M. Alf Museum of Paleontology at The Webb Schools, 1175 West Baseline Road,

11 Claremont, California, 91711, USA

12 Email address: afarke@webb.org 


\section{Abstract}

15 Pterosaurs were widespread during the Late Cretaceous, but their fossils are

16 comparatively rare in terrestrial depositional environments. A large pterosaur bone from the

17 Kaiparowits Formation (late Campanian, 76-74 Ma) of southern Utah, USA, is tentatively

18 identified as an ulna, although its phylogenetic placement cannot be precisely constrained

19 beyond Pterosauria. The element measures over $36 \mathrm{~cm}$ in preserved maximum length, indicating

20 a comparatively large individual with an estimated wingspan between $4.3-5.9 \mathrm{~m}$, the largest

21 pterosaur yet reported from the Kaiparowits Formation. This size estimate places the individual

22 at approximately the same wingspan as the holotype for Cryodrakon boreas from the

23 penecontemporaneous Dinosaur Park Formation of Alberta. Thus, relatively large pterosaurs

24 occurred in terrestrial ecosystems in both the northern and southern parts of Laramidia (western

25 North America) during the late Campanian.

26

27 


\section{Introduction}

29

Pterosaurs were a widespread component of terrestrial ecosystems during the Late Cretaceous, reconstructed as filling a variety of ecological niches (Barrett et al., 2008; Witton \& Naish, 2008). However, the comparative rarity of skeletal material in most formations, due in part to strong taphonomic influences and other geological biases, have limited studies of this clade and clouded interpretations of pterosaur paleobiology and paleoecology (Butler et al., 2012; Butler, Benson \& Barrett, 2013; Dean, Mannion \& Butler, 2016). Thus, even isolated and incomplete bones can provide important information for establishing the distribution and general morphological attributes of pterosaurs (e.g., Kellner et al., 2019).

The Kaiparowits Formation preserves rocks deposited along the eastern margin of Laramidia during the late Campanian ( 76.6-74.5 Ma; Roberts, Deino \& Chan, 2005; Roberts et al., 2013), with significant exposures within Grand Staircase-Escalante National Monument (GSENM) in southern Utah. The formation represents a continental depositional environment preserving river channels, floodplains, and associated settings. A rich fossil record includes exquisitely preserved specimens for numerous tetrapods, including birds, non-avian dinosaurs, crocodylomorphs, turtles, mammals, amphibians, and lepidosaurs (see Titus \& Loewen, 2013, and references therein). Pterosaurs are known from only a handful of specimens. An isolated manual phalanx was the first published record of a pterosaur from the Kaiparowits Formation (Farke \& Wilridge, 2013), suggesting a fairly small ( $<3 \mathrm{~m}$ wingspan) individual. A potential pteranodontoid metacarpal was later reported (McCormack \& Sertich, 2016), as well as the incomplete but associated skeleton of an azhdarchid (Carroll, Farke, Chai, et al., 2017), both of which await formal description. 
Here I report on RAM 22574 (Figure 1), an isolated ?ulna from the largest pterosaur

51 (4.3-5.9 m estimated wingspan) yet known from the Kaiparowits Formation. Although it is only

52 a single bone, this element establishes the size range occupied by the clade in southern Utah

53 during the Late Cretaceous, and expands the known distribution of large pterosaurs across

54 terrestrial environments during the late Campanian of western North America (Figure 2).

Abbreviations. CCMGE, Chernyshev's Central Museum of Geological Exploration,

56

Saint Petersburg, Russia; FHSM, Sternberg Museum of Natural History, Hays, Kansas, USA;

NSM, National Science Museum, Tokya, Japan; RAM, Raymond M. Alf Museum of

Paleontology at The Webb Schools, Claremont, California, USA; RGM, Nationaal

Natuurhistorisch Museum (Naturalis Biodiversity Center), Leiden, The Netherlands; SMK,

Staatliches Museum für Naturkunde, Karlsruhe, Germany; TMM, Texas Memorial Museum, Austin, Texas, USA; TMP, Royal Tyrrell Museum of Palaeontology, Drumheller, Alberta, Canada; ZIN PH, Paleoherpetological Collection, Zoological Institute of the Russian Academy of Sciences, Saint Petersburg, Russia.

\section{Geological Setting}

RAM 22574 was collected at locality RAM V2005022 (colloquially known as the "Cripe

Site"), within the middle unit of the Kaiparowits Formation. This site is a multi-taxon bonebed including multiple associated elements from a tyrannosaurid, at least two hadrosaurids, testudines, and a small ( $\sim 3$ m wingspan) azhdarchid pterosaur (Farke et al., 2016; Carroll, Farke, Chai, et al., 2017).

The bonebed at RAM V2000522 measures over 1 meter in thickness and is interpreted as including at least three main depositional events, with evidence of minor reworking of bones at 
73 the top of the sequence. RAM 22574 was collected at the stratigraphic top of the quarry, $\sim 1.2$

74 meters above the lowest fossil, in a sandy mudstone with extensive clay rip-up clasts and plant

75 debris. The articular surfaces of the bone show some pre-depositional damage, potentially due to

76 fluvial abrasion or decomposition. The fossil was found within $1 \mathrm{~m}$ of an azhdarchid associated

77 skeleton (RAM 15445), partially in the same bedding plane. However, RAM 22574 is from a

78 much larger individual, in that its ulna measures $36 \mathrm{~cm}$ long, versus a radius length (which

79 should be roughly equivalent to ulna length) of around $20 \mathrm{~cm}$ for RAM 15445.

\section{Materials \& Methods}

Collection and preparation. RAM 22574 was collected during the summer of 2016, using standard paleontological excavation techniques. Observations in the field showed that it was damaged prior to burial (described in more detail below). Paraloid B-72 was used to stabilize the fossil in the field, and as a consolidant and glue in the preparation lab. The fossil was mechanically prepared using pneumatic hand tools of various sizes, with final preparation completed using dental picks and pin vices. Fieldwork was conducted under US Bureau of Land Management-Utah paleontology permits UT06-012E-GS and UT06-001S-GS, and the fossil is reposited at the Raymond M. Alf Museum of Paleontology at The Webb Schools, Claremont,

90 California, USA.

91 Comparisons and measurements. Linear measurements of RAM 22574 were collected

92 with a digital calipers, to the nearest millimeter or $0.1 \mathrm{~mm}$ (Figure 3; Table 1). Circumference

93 was measured to the nearest millimeter with a cloth measuring tape. For anatomical

94 comparisons, casts of Montanazhdarcho minor (MOR 691) and Quetzalcoatlus northropi (TMM

95 41450) were compared directly with RAM 22574. 
Wingspan estimation. The wingspan of RAM 22574 was approximated by scaling from

97 relatively complete wings of pterodactyloid pterosaurs. Here, wing length is calculated as the

98 sum of all sequential forelimb long bone lengths (humerus, ulna, metacarpal IV, phalanges in

99 digit IV, excluding the carpals). Wingspan is approximated by doubling wing length. As noted

100 by Hone and Benton (2007), this neglects the width of the torso, but that is offset in part by the

101 flexion of the wings in life. Data (Table 1) were taken from measurements published by Unwin

102 et al. (2000) and Bennett (2001a). Assuming that RAM 22574 was an ulna, each wing was scaled

103 by ulna size for that specimen. To reduce concerns about allometry, only specimens in the

104 approximate size range of RAM 22574 were used ( $<25 \%$ difference in ulnar length). Because

105 RAM 22574 was slightly "telescoped", two calculations were run — one with the bone length as

106 preserved, and another adding an additional $15 \mathrm{~mm}$ to the bone length to accommodate the

107 effects of the crushing. Finally, the wingspan of Cryodrakon boreas (TMP 1992.83.4) was

108 estimated by scaling the holotype humerus (measurements from Godfrey \& Currie, 2005)

109 relative to the humerus for Quetzalcoatlus sp. (TMM 42422).

110

\section{Results}

\section{Systematic Paleontology}

113 Archosauria Cope, 1869 sensu Gauthier and Padian, 1985

114 Pterosauria Kaup, 1834 sensu Sereno, 1991

115 Referred material. RAM 22574, a nearly complete ?ulna (Figure 1).

116 Locality and horizon. Locality RAM V2005022, the "Cripe Site," located within Grand

117 Staircase-Escalante National Monument, Garfield County, Utah (Figure 2). The site is situated in 
118 the middle unit of the Kaiparowits Formation, which is late Campanian in age (Roberts, Deino \&

119 Chan, 2005; Roberts et al., 2013).

120 Identification. This fossil is identified confidently as a pterosaur limb bone, and

121 tentatively as an ulna. Because the descriptive terminology hinges upon these assumptions, I first

122 address the underlying logic.

123 RAM 22574 is clearly hollow, which for the Late Cretaceous restricts possible

124 identifications to either Theropoda or Pterosauria. The extremely thin cortical bone (between 0.7

125 and $1.7 \mathrm{~mm}$ ) relative to the size of the element is distinct to pterosaurs versus their outgroup

126 clades (Unwin, 2003), particularly for elements of this size. Thus, the identification to

127 Pterosauria is quite confident.

128 Because key parts of RAM 22574 were damaged prior to fossilization (see below),

129 identification of this bone within the skeleton is less certain. It is clearly a limb bone (rather than

130 vertebra, ribs, or cranial material), but does not match well with morphology expected for any of

131 the hind limb elements. There is nothing that resembles either the head or distal end of the femur,

132 nor the somewhat sigmoid, relatively slender profile of a typical pterosaur femur. The overall

133 robustness of the bone (proportions of length vs. width) differs sharply from that seen in the tibia

134 and fibula for typical Late Cretaceous pterosaurs of this size range (e.g., Bennett, 2001b;

135 Averianov, 2010). A humerus can be excluded on the basis of a lack of a deltopectoral crest or

136 the bulbous distal articular surface processes. Neither articular end shapes or element proportions

137 fall within what would be expected for metacarpals or phalanges, regardless of clade. Thus, a

138 radius or ulna seems to be the most likely identification.

139 The more heavily pre-depositionally damaged end of RAM 22574 shows topographic

140 complexity that differs from what is seen in typical pterosaur radii (Wellnhofer, 1991; Bennett, 
141 2001b; Veldmeijer, 2003). A prominent protrusion (labeled as ?vc on Figure 1B, C) resembles a

142 similar expansion associated with the ventral cotylus seen in Montanazhdarcho minor (MOR

143 691, personal observation on cast; ulnar facet/fossa of McGowen et al., 2002) and also an ulna

144 referred to Cryodrakon boreas (TMP 1965.14.398; Godfrey \& Currie, 2005; Hone, Habib \&

145 Therrien, 2019). The relatively restricted nature of this protrusion differs from the more elongate,

146 tab-like anterior tuberosity seen on a radius referred to Azhdarcho lancicollis (CCMGE 8/11915;

147 see fig. 26 in Averianov, 2010).

148 The overall proportions (element length vs. maximum diaphyseal width) of RAM 22574

149 also are more similar to that of an ulna than a radius. For instance, Quetzalcoatlus northropi

150 (TMM 41450) shows that radii tend to be far more slender (proportionately) than ulnae. Similar

151 proportions are seen in Montanazhdarcho minor, Azhdarcho lancicollis, Maaradactylus

152 spielbergi, and also in Pteranodon spp. (Bennett, 2001b; McGowen et al., 2002; Veldmeijer,

153 2003; Averianov, 2010), as a few examples. In the Maaradactylus spielbergi holotype RGM

154 401880; Veldmeijer, 2003), which has approximately the same ulnar length as the length of

155 RAM 22574, the dorso-ventral diaphyseal diameter to maximum element length ratio is around

1560.076 for the ulna and 0.033 for the radius. The same ratio is approximately 0.13 in RAM 22574

157 (see Table 1).

158 Assuming that RAM 22574 is an ulna, it can be tentatively identified as a right element,

159 based on the position of a roughened area on the ?proximal end that may represent the bicipital

160 tuberosity (labeled as ?bt on Figure 1C). This area should towards the ventral edge of the

161 element's anterior surface, as seen in other pterosaurs (e.g., Azhdarcho lancicollis, ZIN PH

162 41/44; see fig. 25 in Averianov, 2010). 
Description. RAM 22574 measures $366 \mathrm{~mm}$ in maximum preserved length. As outlined

164 above, this description assumes that RAM 22574 is a right ulna, so that directional and

165 anatomical terminology follow accordingly. Both proximal and distal ends were slightly abraded

166 prior to fossilization, with the proximal end more severely damaged. Part of this end was broken

167 open prior to burial, as evidenced by some rip-up clay clasts inside the bone as well as field

168 observations of the incomplete element by the author. Little of the actual articular surface is

169 preserved on either end. Surface bone texture for the shaft is smooth rather than porous, and no

170 open epiphyses are visible, suggesting osteological maturity for this individual (although not

171 definitively so).

172 The proximal end of the element is mostly incomplete, preserving only a portion of what

173 is interpreted as the ventral cotylus. The cotylus projects anteriorly, with much of its articular

174 surface abraded away. A roughened patch of bone around $20 \mathrm{~mm}$ distal to the peak of the cotylus

175 may represent the bicipital tuberosity, for attachment of m. biceps brachii (Figure 1C). There is

176 no evidence of pneumatic foramina on the proximal end of RAM 22574, but the area where such

177 foramina would be expected is broken.

178 The shaft broadens gradually from the proximal to the distal end of the element (Figure

$1791 \mathrm{C}, \mathrm{F}, \mathrm{G})$, although this appears accentuated in part by crushing. At mid-shaft, the cross-section

180 is oval and elongated in the dorso-ventral direction (width/height ratio of 0.51; see Table 1). At

181 the distal third of the bone, cortical thickness ranges from 1.0 to $1.6 \mathrm{~mm}$; at the proximal third, it

182 is $1.7 \mathrm{~mm}$ thick. At least part of the shaft is mildly telescoped through proximo-distal distortion,

183 as shown by displacement around the shaft. This would add another $15 \mathrm{~mm}$ or so to the total

184 length of the bone. The distal third of the shaft in RAM 22574 is flattened on its ventral surface.

185 This is somewhat accentuated by crushing, but appears to be at least partly original morphology. 
this depression appears accentuated by crushing. After accounting for the space between the

\section{Discussion}

Unfortunately, the incomplete and crushed nature of RAM 22574 limits interpretation of

the element and the animal. In general, neither the radius nor ulna exhibit major diagnostic features in pterosaurs, so the element cannot currently be identified beyond Pterosauria. Nevertheless, RAM 22574 does represent the largest pterosaur bone yet known from the Kaiparowits Formation and only the second formally described element, and is thus useful for documenting the size of some of the pterosaurs in the Kaiparowits ecosystem. boreas (TMP 92.83.4; late Campanian, Dinosaur Park Formation, Alberta); the ulna of RAM m wingspan for Montanazhdarcho minor (late Campanian, Two Medicine Formation, Montana), 
209 boreas as one of the larger pterosaur individuals known from late Campanian-aged terrestrial

210 deposits of North America. Furthermore, it demonstrates that pterosaurs in this size range

211 occurred in ecosystems both in the northern and southern parts of Laramidia (western North

212 America) during the late Campanian (see Figure 2). RAM 22574 is nonetheless from an

213 individual smaller than the largest referred element of $C$. boreas (TMP 1980.16.1367), which

214 may have matched some of the largest azhdarchids in size (Hone et al. 2019). This indicates

215 potential for truly gigantic pterosaurs ( $\square \geq 10 \mathrm{~m}$ wingspan) across terrestrial environments in

216 North America. Future discoveries will undoubtedly help clarify phylogenetic relationships

217 between pterosaurs living in terrestrial environments at this time, to see if they were relatively

218 geographically restricted, or if individual species had continent-level ranges. Additionally, more

219 work is required to determine if large pterosaurs played similar ecological roles across their 220 various environments.

\section{Acknowledgments}

This specimen would never have been revealed without the sharp eyes of Jeff Cripe, who

224 discovered the locality where this bone was collected. The 2016 field crew of volunteers and 225 museum staff from the Alf Museum assisted in collection of this fossil, and Jared Heuck skillfully completed preparation. Discussions with Dave Hone, Nate Carroll, and others were helpful in establishing and confirming the identity of this fossil. I thank Valeria Pellicer for her renderings of the bone. Fieldwork in GSENM was completed under US Bureau of Land Management paleontology permits UT06-012E-GS and UT06-001S-GS, with facilitation by Alan Titus and Greg MacDonald. Editorial comments by Graciela Piñeiro and reviewer

231 comments by Dave Hone, Felipe Pinheiro, and Sterling Nesbitt improved and clarified an earlier 
232 version of this manuscript. Finally, I thank Frank Varriale for being my "writing buddy" who 233 helped push this project to completion.

234

235 References

236 Averianov AO. 2010. The osteology of Azhdarcho lancicollis Nessov, 1984 (Pterosauria, Azhdarchidae) from the late Cretaceous of Uzbekistan. Proceedings of the Zoological Institute of the Russian Academy of Sciences 314:264-317.

Barrett PM, Butler RJ, Edwards NP, Milner AR. 2008. Pterosaur distribution in time and space: an atlas. Zitteliana B28:61-107.

241 Bennett SC. 2001a. The osteology and functional morphology of the Late Cretaceous pterosaur Pteranodon Part II. Size and functional morphology. Palaeontographica Abteilung A 260:113-153.

244 Bennett SC. 2001b. The osteology and functional morphology of the Late Cretaceous pterosaur Pteranodon Part I. General description of osteology. Palaeontographica Abteilung A 260:1-112.

247 248

Butler RJ, Benson RBJ, Barrett PM. 2013. Pterosaur diversity: Untangling the influence of sampling biases, Lagerstätten, and genuine biodiversity signals. Palaeogeography, Palaeoclimatology, Palaeoecology 372:78-87. DOI: 10.1016/j.palaeo.2012.08.012.

Butler RJ, Brusatte SL, Andres B, Benson RBJ. 2012. How do geological sampling biases affect studies of morphological evolution in deep time? A case study of pterosaur (Reptilia: Archosauria) disparity. Evolution 66:147-162. DOI: 10.1111/j.1558-5646.2011.01415.x. 
253 Carroll N, Farke AA, Chai S, Oei A. 2017. A new azhdarchid pterosaur from the Kaiparowits

254 Formation (late Campanian) of southern Utah, USA. Journal of Vertebrate Paleontology,

$255 \quad$ Program and Abstracts 2017:94.

256 Cope ED. 1869. Synopsis of the extinct Batrachia, Reptilia, and Aves of North America. Transactions of the American Philosophical Society 14:1-252.

258

259

260

261

262

263

264

265

266

267

268

269

270

271

272

273

274

Dean CD, Mannion PD, Butler RJ. 2016. Preservational bias controls the fossil record of pterosaurs. Palaeontology 59:225-247. DOI: 10.1111/pala.12225.

Farke AA, Chai S, Diepenbrock J, Gonzalez D. 2016. From the quarry to the classroom: a case study in field- and museum-centered research for high school students. Journal of Vertebrate Paleontology, Program and Abstracts 2016:191.

Farke AA, Wilridge CA. 2013. A possible pterosaur wing phalanx from the Kaiparowits Formation (late Campanian) of southern Utah, USA. PalArch's Journal of Vertebrate Palaeontology 10:1-6.

Gauthier J, Padian K. 1985. Phylogenetic, functional, and aerodynamic analyses of the origin of birds and their flight. In: Hecht JHOMK, Viohl G, Wellnhofer P eds. The Beginning of Birds. Eichstatt: Freunde des Jura Museums, 185-197.

Godfrey SJ, Currie PJ. 2005. Pterosaurs. In: Currie PJ, Koppelhus EB eds. Dinosaur Provincial Park: A Spectacular Ancient Ecosystem Revealed. Bloomington, Indiana: Indiana University Press, 292-311.

Hone DWE, Benton MJ. 2007. Cope's Rule in the Pterosauria, and differing perceptions of Cope's Rule at different taxonomic levels. Journal of Evolutionary Biology 20:11641170. DOI: $10.1111 / \mathrm{j} .1420-9101.2006 .01284 . x$. 
275 Hone DWE, Habib MB, Therrien F. 2019. Cryodrakon boreas, gen. et sp. nov., a Late

276 Cretaceous Canadian azhdarchid pterosaur. Journal of Vertebrate Paleontology

277 39:e1649681. DOI: 10.1080/02724634.2019.1649681.

278 Kaup JJ. 1834. Versuch einer Eintheilung der Saugethiere in 6 Stämme und der Amphibien in 6 279 Ordnungen. Isis 3:311-315.

280

281

282

283

284

285

286

287

288

289

290

291

292

293

294

295

296

297

Kellner AWA, Rodrigues T, Costa FR, Weinschütz LC, Figueiredo RG, Souza G a. D, Brum AS, Eleutério LHS, Mueller CW, Sayão JM, Kellner AWA, Rodrigues T, Costa FR, Weinschütz LC, Figueiredo RG, Souza G a. D, Brum AS, Eleutério LHS, Mueller CW, Sayão JM. 2019. Pterodactyloid pterosaur bones from Cretaceous deposits of the Antarctic Peninsula. Anais da Academia Brasileira de Ciências 91:e20191300. DOI: 10.1590/0001-3765201920191300.

McCormack L, Sertich JJW. 2016. A possible late Campanian record of Pteranodontia from the Kaiparowits Formation of Grand Staircase-Escalante National Monument, southern Utah. Journal of Vertebrate Paleontology, Program and Abstracts 2016:186.

McGowen MR, Padian K, Sosa MAD, Harmon RJ. 2002. Description of Montanazhdarcho minor, an azhdarchid pterosaur from the Two Medicine Formation (Campanian) of Montana. PaleoBios 22:1-9.

Roberts EM, Deino AL, Chan MA. 2005. 40Ar/39Ar age of the Kaiparowits Formation, southern Utah, and correlation of contemporaneous Campanian strata and vertebrate faunas along the margin of the Western Interior Basin. Cretaceous Research 26:307-318.

Roberts EM, Sampson SD, Deino A, Bowring S, Buchwaldt R. 2013. The Kaiparowits Formation: a remarkable record of Late Cretaceous terrestrial environments, ecosystems and evolution in Western North America. In: Titus AL, Loewen MA eds. At the Top of 
the Grand Staircase: The Late Cretaceous of Southern Utah. Bloomington, Indiana: Indiana University Press, 85-106.

300 Sereno PC. 1991. Basal archosaurs: phylogenetic relationships and functional implications. Journal of Vertebrate Paleontology 10 (supplement to 3):1-53. DOI: 10.2307/3889336.

302 Sullivan RM, Fowler DW. 2011. Navajodactylus boerei, n. gen., n. sp.,

Titus AL, Loewen MA. 2013. At the Top of the Grand Staircase: The Late Cretaceous of Southern Utah. Bloomington, Indiana: Indiana University Press.

Unwin DM. 2003. On the phylogeny and evolutionary history of pterosaurs. Geological Society, London, Special Publications 217:139-190. DOI: 10.1144/GSL.SP.2003.217.01.11.

Unwin DM, Lü J, Bakhurina NN. 2000. On the systematic and stratigraphic significance of pterosaurs from the Lower Cretaceous Yixian Formation (Jehol Group) of Liaoning, China. Mitteilungen aus dem Museum für Naturkunde, Berlin, Geowissenschafilichen Reihe 3:181-206. DOI: 10.1002/mmng.20000030109.

314 Veldmeijer AJ. 2003. Coloborhynchus spielbergi sp. nov. (Pterodactyloidea) from the Albian (Lower Cretaceous) of Brazil. Scripta Geologica 125:35-139.

316 Wellnhofer P. 1991. Weitere Pterosaurierfunde aus der Santana-Formation (Apt) der Chapada do Araripe, Brasilien. Palaeontographica Abteilung A 215:43-101.

318 Witton MP, Naish D. 2008. A reappraisal of azhdarchid pterosaur functional morphology and paleoecology. PLOS ONE 3:e2271. DOI: 10.1371/journal.pone.0002271. 


\section{Figure 1}

RAM 22574, ulna of Pterosauria indet.
A) ?dorsal; B) ?proximal;
; C) ?anterior;
D) ?distal;
E) ?ventral; and F) ?posterior views; with G) showing interpretive drawing of ?posterior view, including missing parts; and $\mathrm{H}$ ) showing restored view of bone in ?posterior view. Scale bars equal $10 \mathrm{~cm}$. Abbreviations: ?bt, ?bicipital tuberosity; ?dist, ?distal end; ?prox, ?proximal end; ?vc, ?ventral cotylus.

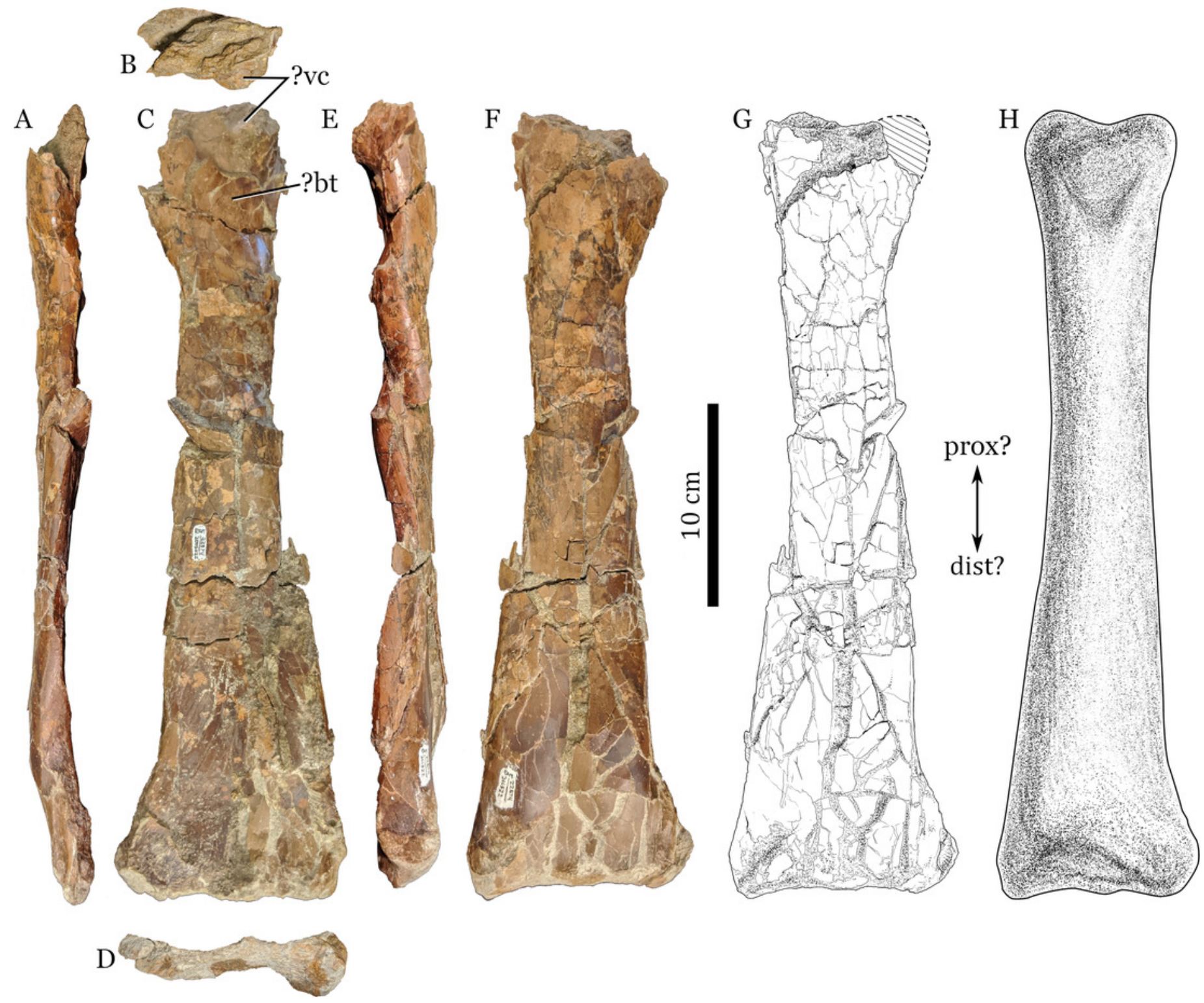




\section{Figure 2}

Significant discoveries of pterosaurs from late Campanian terrestrial depositional environments in western North America.

Silhouettes are scaled to maximum estimates of wingspan for individual specimens (see Discussion and Table 2). The silhouette for RAM 22574 shows the minimum (black) and maximum (green) size estimates for the specimen (Table 2). Cryodrakon boreas is scaled to the holotype (black), with the 10 meter wingspan estimate (gray) for the largest known specimen (TMP 1980.16.1367) patterned after Quetzalcoatlus northropi. The silhouette is modified from an image of Quetzalcoatlus by Mark P. Witton and Darren Naish (licensed under CC BY 3.0 Unported via http://phylopic.org/ ); note that body shape may have varied greatly across the taxa depicted here. 


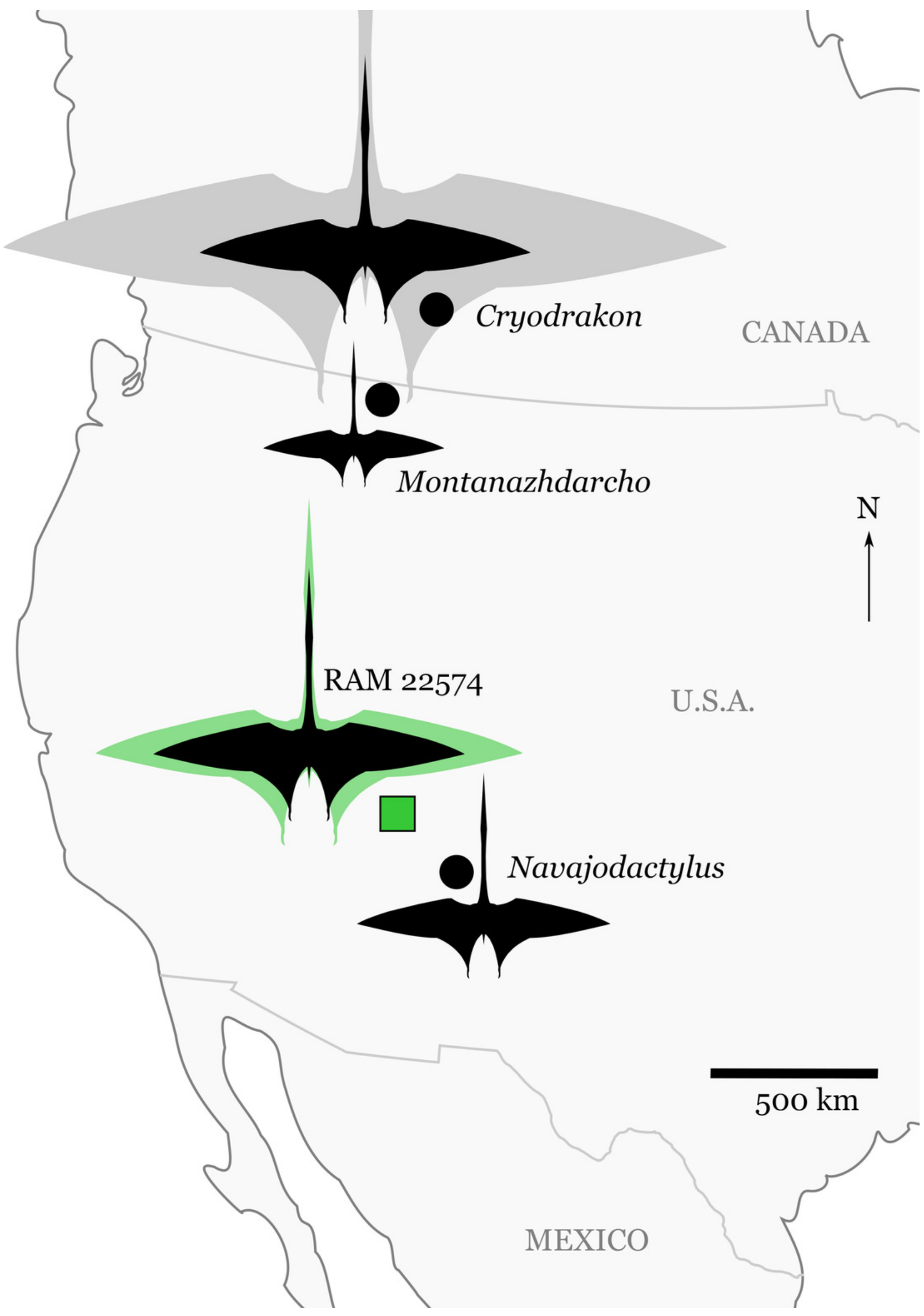




\section{Figure 3}

Interpretive drawing of RAM 22574, showing measurements taken here.

Measurements include: $1 \mathrm{a}$, maximum proximo-distal length; $1 \mathrm{~b}$, maximum proximo-distal length (adjusting for telescoping); 2, maximum dorso-ventral width of proximal end; 3 , minimum antero-posterior width of proximal end; 4 , antero-posterior width of proximal end at ventral cotyle; 5 , dorso-ventral width at narrowest point of shaft; 6 , dorso-ventral width at mid-shaft; 7, antero-posterior width at mid-shaft; 8, circumference at mid-shaft; 9, maximum dorso-ventral width of distal end; 10, maximum antero-posterior width of distal end; 11, minimum antero-posterior width of distal end. Data are provided in Table 1.

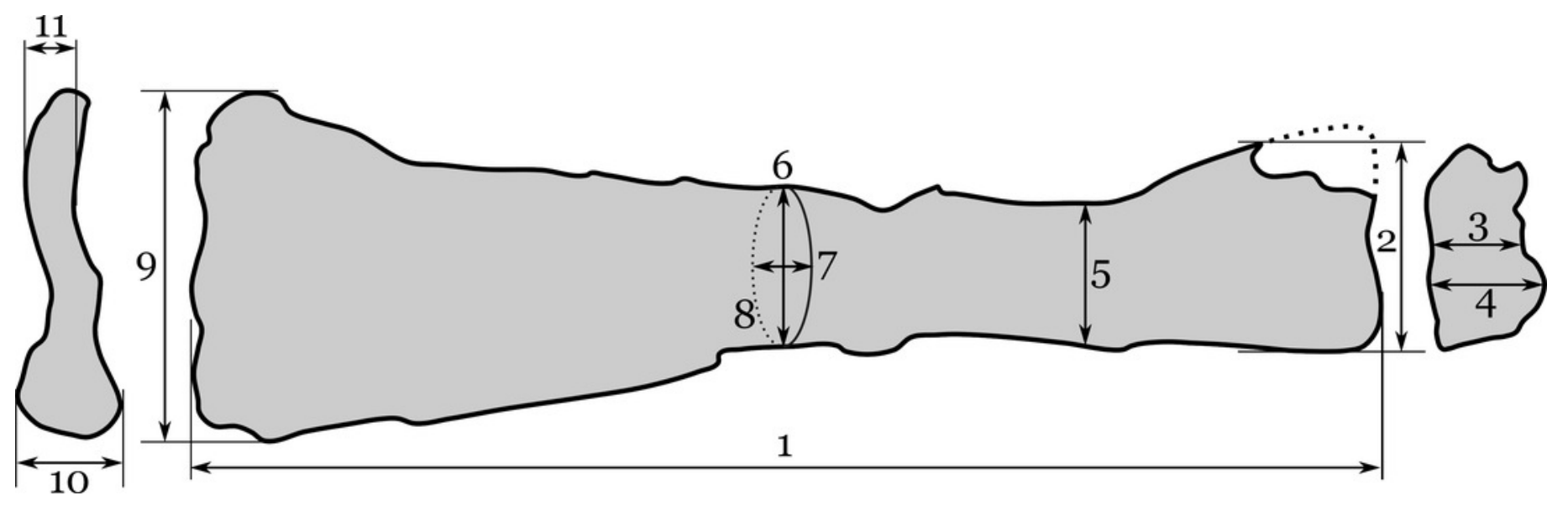




\section{Table $\mathbf{1}$ (on next page)}

Measurements of pterosaur ?ulna, RAM 22574, in millimeters.

All measurements were taken with sliding digital calipers, except for 6 , which was measured with a cloth measuring tape. See Figure 3 for explanation of measurements. 
1a Maximum proximo-distal length (as preserved) 366

1b Maximum proximo-distal length (adjusting for telescoping) 381

2 Maximum dorso-ventral width of proximal end (as preserved) 71

3 Minimum antero-posterior width of proximal end (as preserved) 32

4 Antero-posterior width of proximal end at ventral cotyle 48

5 Dorso-ventral width at narrowest point of shaft 49

6 Dorso-ventral width at mid-shaft (as preserved) 52

7 Antero-posterior width at mid-shaft (as preserved)

8 Circumference at mid-shaft (as preserved)

133

9 Maximum dorso-ventral width of distal end (as preserved) 106

10 Maximum antero-posterior width of distal end (as preserved)

11 Minimum antero-posterior width of distal end (as preserved) 


\section{Table 2 (on next page)}

Comparative measurements of selected pterodactyloid pterosaurs, with wingspan for RAM 22574 scaled from those measurements.

Two ulna lengths are provided for RAM 22574, representing the element as preserved (the smaller number) and a second estimate accounting for mild telescoping that reduced the preserved length of the element. Measurements for Pteranodon are taken from Bennett (2001a), and those for Cryodrakon are from Godfrey and Currie (2005); all others are from Unwin et al. (2000). Measurements are in millimeters, except for wingspan estimates, which are in meters. Abbreviations: $H$, humerus length; MC-IV, metacarpal IV; IV-1,-2,-3,-4, fourth digit manual phalanges 1 through 4; RAM WS, range of wingspans estimated for RAM 22574 based on direct scaling from each specimen; WS, wingspan (calculated by summing forelimb bone lengths and multiplying by 2 ). 


\begin{tabular}{|c|c|c|c|c|c|c|c|c|c|}
\hline Taxon & Specimen & $\mathbf{H}$ & $\mathbf{U}$ & MC-IV & IV-1 & IV-2 & IV-3 & IV-4 & RAM WS \\
\hline $\begin{array}{l}\text { Arthurdactylus } \\
\text { conandoylei }\end{array}$ & $\begin{array}{l}\text { SMK } 1132 \\
\text { PAL }\end{array}$ & 230 & 312 & 227 & 445 & 402 & 312 & $2754.41 \mathrm{~m}$ & $5.2-5.4 \mathrm{~m}$ \\
\hline $\begin{array}{l}\text { Anhanguera } \\
\text { santanae }\end{array}$ & $\begin{array}{l}\text { NSM PV } \\
19892\end{array}$ & 257 & 384 & 257 & 462 & 387 & 270 & $2254.48 \mathrm{~m}$ & $4.3-4.5 \mathrm{~m}$ \\
\hline $\begin{array}{l}\text { Cryodrakon } \\
\text { boreas }\end{array}$ & $\begin{array}{l}\text { TMP } \\
1992.83 .4\end{array}$ & 245 & & & & & & $\begin{array}{r}4.57 \mathrm{~m} \\
\text { (est.) }\end{array}$ & \\
\hline Pteranodon sp. & FHSM 184 & 269 & 393 & 583 & 653 & 539 & 390 & $1946.04 \mathrm{~m}$ & $5.9 \mathrm{~m}$ \\
\hline $\begin{array}{l}\text { Quetzalcoatlus } \\
\text { sp. }\end{array}$ & TMM 42422 & 250 & 358 & 620 & 602 & 305 & 156 & $394.66 \mathrm{~m}$ & $4.8-5.0 \mathrm{~m}$ \\
\hline $\begin{array}{l}\text { Pterosauria } \\
\text { indet. }\end{array}$ & RAM 22574 & & $\begin{array}{l}366 / \\
381\end{array}$ & & & & & & $4.3-5.9 \mathrm{~m}$ \\
\hline
\end{tabular}

